\title{
IHI Open School's quality improvement initiative
}

\author{
Hope Olivia Ward third year medical student ${ }^{1}$, Aled Jones senior lecturer ${ }^{2}$, Andrew Carson-Stevens \\ clinical lecturer ${ }^{3}$
}

${ }^{1}$ Cardiff University School of Medicine, Cardiff CF14 4XW, UK; ${ }^{2}$ School of Nursing and Midwifery Studies, College of Biomedical and Life Sciences, Cardiff University, Cardiff, UK; ${ }^{3}$ Institute of Primary Care and Public Health, School of Medicine, Cardiff University, Cardiff, UK

The Francis report reflects the need for students, like all members of the healthcare team, "to make the protection of patients their priority." ${ }^{2}$ Since 2008, when the Institute for Healthcare Improvement (IHI) Open School opened its virtual doors, more than 150000 students and faculty across the world have accepted this call. ${ }^{3}$ The school provides online courses in quality improvement, patient safety, and leadership, as well as support for local interprofessional communities of learning called "chapters." We recommend the IHI Open School, which offers a cost effective alternative to more expensive resources that provide similar content, as an incubator of change.

In the 43 chapters in UK hospitals and universities, healthcare students act as change agents within the NHS. For example, medical students at Cardiff University have been learning about quality improvement methodology and how their actions can affect patient care. One activity involved students asking every patient they met one question-"What can I do to improve your stay?"- and acting on the response at the bedside. The students are making simple changes that are having a big impact on patients' experiences. However, these student led efforts can exist only with support from - and partnering between - higher education institutions and healthcare organisations. With support and coordination from educators (undergraduate and postgraduate) and healthcare organisations, tomorrow's healthcare professionals stand a chance of being architects capable of improving the systems within which they work. The emerging partnerships that reflect this across the UK need nurturing.

We believe that successful partnerships between healthcare and various institutions of learning will lead to many benefits- to the NHS, universities, and patients and their families-as envisioned by Francis.

Competing interests: HOW is an IHI Open School chapter leader at Cardiff University. AJ is the Wales faculty leader of the IHI Open School. AC-S is the UK and Ireland regional leader of the IHI Open School.

1 Coombes R. Francis interview: what doctors must learn from my report. $B M J$ 2013;346:f878. (8 February.)

2 Francis R. The Mid-Staffordshire NHS Foundation Trust Public Inquiry. Final report. 2013. www.midstaffspublicinquiry.com/.

3 Institute for Healthcare Improvement Open School. Overview. 2013. www.hi.org/offerings/ IHIOpenSchool/overview/Pages/default.aspx.

Cite this as: BMJ 2013;346:f1371

๑ $\odot$ BMJ Publishing Group Ltd 2013 